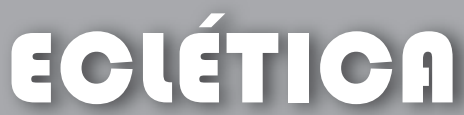 química
}

\section{CARACTERÍSTICAS FÍSICO-QUÍMICAS DE ÁCIDOS HÚMICOS EM DIFERENTES ETAPAS DA VERMICOMPOSTAGEM}

\author{
C. R. G. Brighenti ${ }^{1}$, E. L. Reis ${ }^{2}$ e C. Reis ${ }^{2}$ \\ 1- Departamento de Engenharia de Biossistemas - Universidade Federal de São João Del Rei \\ Praça Dom Helvécio, 74, CEP: 36301-160 São João Del Rei - MG \\ e-mail: carlabrighenti@ufsj.edu.br \\ 2- Departamento de Química - Universidade Federal de Viçosa - Viçosa - MG \\ e-mail:efraim@ufv.br
}

\begin{abstract}
Resumo: Amostras de materiais coletados em diferentes estádios de vermicompostagem foram submetidas a procedimentos de extração de ácidos húmicos. Técnicas de titulação potenciométrica, termogravimetria (DTG), difração de raios X e espectrofotometria no uv/visível e no infravermelho foram utilizadas no estudo desses materiais. Os dados de titulação foram submetidos ao ajuste por regressão não-linear, determinando-se, assim, cinco valores de pKa característicos de cinco classes de grupos tituláveis. Nas curvas DTG, foram observadas duas etapas, sendo a primeira característica da separação de estruturas alifáticas e, ou, alicíclicas e a segunda, a decomposição de estruturas aromáticas. A difratometria de raios $\mathrm{X}$ apresentou diferenças marcantes nos resultados, principalmente nos três primeiros picos onde parecem ocorrer reorganização estrutural e polimerização ao longo do processo de vermicompostagem. Os espectros do infravermelho não apresentaram diferenciação entre os espectros. Os valores da razão $\mathrm{E}_{4} / \mathrm{E}_{6}$ encontrados estão de acordo com os característicos dos ácidos húmicos, mas não fornecem informações que possam contribuir para a elucidação da estrutura e formação desses ácidos.
\end{abstract}

Palavras-chave: titulação, termogravimetria, difração, espectrofotometria, regressão não-linear.

Introdução

A transformação da matéria orgânica, resultante da ação combinada das minhocas do tipo Eisenia foetida e da microflora que vive em seu trato digestivo, é conhecida como vermicompostagem. O valor agronômico do vermicomposto, quanto às características físico-químicas, é compatível com as características dos compostos convencionais, porém atinge mais rapidamente o estádio de maturação[1]. A maturação é a segunda fase do processo em que ocorre a humificação dos intermediários mais estáveis e a redução dos or- ganismos patogênicos remanescentes, melhorando a qualidade do produto final [2]. Nesta fase há formação de ácidos húmicos (AH). A composição elementar do ácido húmico é $\mathrm{C}_{308} \mathrm{H}_{328} \mathrm{O}_{90} \mathrm{~N}_{5}$, com a massa molecular de 5.539,949 $\mathrm{g} \mathrm{mol}^{-1}$ e análise elementar de $66,78 \%$ C, 5,97\% H, 25,99\% O e $1,26 \% \mathrm{~N}$ [3].

Dentre alguns métodos utilizados para caracterização de macromoléculas, aplicados ao estudo de substâncias húmicas, destacam-se: titulação, termogravimetria, difratometria e espectrofotometria no uv-visível e infravermelho [4]. 
As curvas de titulação de substâncias húmicas não apresentam pontos de inflexão bem definidos, dificultando a aplicação de métodos clássicos da primeira e segunda derivada. Titulações levadas até um $\mathrm{pH}$ preestabelecido também estão sujeitas a erros devido à ampla faixa de $\mathrm{pK}$ dos grupos ionizáveis [5]. Para quantificar a estequiometria e as constantes de ionização condicionais dos grupos ionizáveis em substâncias húmicas, os dados das titulações potenciométricas devem ser tratados por métodos numéricos baseados em regressão linear ou não-linear [6].

As análises termogravimétricas permitem estudar a estabilidade térmica e estimar o grau de aromaticidade do material húmico [7]. Com a perda de massa registrada abixo de $673 \mathrm{~K}$, devida à desidrsão e à eliminãa de grupantfuncionais das partes alifáticas, uma estimativa do "grau de aromaticidade" pode ser obtida, deter"grau de aromaticidade" pode ser obtida, deter-
minando-se a perda de massa acima de $673 \mathrm{~K}$ [8].

As análises de difração de raios $\mathrm{X}$ têm sido utilizadas para caracterizar a natureza dos compostos húmicos dos solos e o produto de suas interações com metais.

No DRX normalmente ocorrem picos fracos e linhas difusas [9].

Em função da grande quantidade e variabilidade de grupos cromóforos existentes nas macromoléculas húmicas, os espectros obtidos no uv/visível são geralmente formados pela sobreposição de várias bandas, sem picos definidos [10]. $\mathrm{Na}$ faixa do visível, as absorbâncias em 465 e $665 \mathrm{~nm}$ e a relação entre estas $\left(E_{4} / E_{6}\right)$ têm sido usadas para caracterização de substâncias húmicas [4]. Segundo Chen, Senesi e Schnitzer [11], a razão $E_{4} / E_{6}$ está relacionada ao tamanho e ao peso molecular das substâncias húmicas. Stevenson [12] relatou que a razão $E_{4} / E_{6}$ diminui com $o$ aumento do peso molecular e com a quantidade de estruturas aromáticas.

Outro método utilizado para caracterização de substâncias húmicas é o in- fravermelho com transformada de Fourier (FTIR). Embora existam diferenças entre os espectros, a feição geral é bastante similar, ocorrendo variações nas proporções entre os sinais e pequenos deslocamentos na freqüência de absorção [10]. A informação provida pela análise comparativa entre espectros é de maior valia que a análise isolada.

Neste trabalho, pretendeu-se caracterizar fisico-quimicamente ácidos húmicos extraídos ao longo do processo de vermicompostagem, sendo feita inicialmente a extração dos ácidos a partir da metodologia proposta pela Sociedade Internacional de Substâncias Húmicas, seguida pela titulacão potenciométrica, espectrometria por difração de raios $x$, termogravimetria e espe por difração de ras/visíve objetivo de distinguir diferentes grupos carboxílicos, fenólicos e amínicos e determinar se o vermicomposto atingiu grau satisfatório de estabilização.

\section{Materiais e Métodos}

\section{Obtenção das amostras}

As amostras foram obtidas no minhocário MINHOBOX ${ }^{\circledR}$ situado em Juiz de Fora - MG, que utiliza o sistema de minhocultura verticalizada em caixas, em que o esterco é curtido durante 35 dias em leiras prismáticas montadas em canteiros e depois de atingir cor e granulometria estabelecida é adicionado em caixas organizadas em prateleiras, com capacidade para $62,5 \mathrm{~L}$ de esterco previamente curtido e $2 \mathrm{~L}$ de minhoca em cada caixa, onde permanece por mais 28 dias.

\section{Coleta da amostra}

Foram separadas três leiras (denominadas $\mathrm{S}$, T e Q) em que se efetuou o reviramento das leiras a cada dois dias. A coleta foi realizada de sete em sete dias.
Coletaram-se amostras desde o dia da montagem das leiras com a matéria-prima crua (esterco bovino) até a total humificação da matéria orgânica e obtenção do vermicomposto propriamente dito, num to ostras, sendo 10 amostras de cada leira.

3. Extração de ácidos húmicos

Depois de seca ao ar por 24 horas, cad amostra foi triturada e pulverizada em grau de porcelana e passada em peneira de 80 mesh. As frações pulverizadas foram embaladas, etiquetadas separadamente em frascos de vidro e armazenadas em refrigerador a $3^{\circ} \mathrm{C}$

Pesaram-se $30 \mathrm{~g}$ de amostra de vermicomposto, colocando em agitação com $150 \mathrm{~mL}$ de $\mathrm{NaCl} 0,5 \mathrm{~mol} \mathrm{~L}^{-1}$ por 4 horas em atmosfera de nitrogênio para pré-lavagem das amostras. Em seguida, centrifugou-se a mistura, descartando o soguida, centrifugou-se a mistura, descartando o so-
brenadante. Diluiu-se o resíduo sólido em $300 \mathrm{~mL}$ brenadante. Diluiu-se o resíduo sólido em $300 \mathrm{~mL}$ de $\mathrm{NaOH}$ 0,1 mol L ${ }^{-1}$, colocando-o em agitação
por 20 horas, em atmosfera de $\mathrm{N}_{2}$, para evitar por 20 horas, em atmosfera de $\mathrm{N}_{2}$, para evitar horas, centrifugou-se o material a $5.000 \mathrm{~g}$ (FCRmédia) por 20 minutos. Recolheu-se o sobrenadante, e imediatamente reduziu-se o $\mathrm{pH}$ para 2,0, por gotejamento de solução aquosa de $\mathrm{HCl}$ 1:1. Esse gotejan extrato foi mantido no refigerador. O resíduo sólido foi movanente submetido à extração, da mesma forma. Esse sobrenadante foi misturado ao anterior, ajustando-se novamente o $\mathrm{pH}$ para 2,0. $\mathrm{O}$ extrato acidificado foi deixado em geladeira para precipitação dos AHs. Após 18 horas, retirou-s por sifonação o excesso de sobrenadante (fração ácido fúlvico), que foi descartado. Centrifugou-se o restante do material a $5.000 \mathrm{~g}(\mathrm{FCR}$ ) por 10 minutos, eliminando o sobrenadante. Ressobia zou-se o ácido húmico em 300 mL de soluc̃ão zolução NaOH 0,1 L L $^{-1}$ en ans o process o dutução $\mathrm{HCl} 0,01 \mathrm{~mol} \mathrm{~L}^{-1}$ até a clarificação do sobrenadante, que foi levado para o congelador até a sua solidificação. Algumas horas depois, cada amostra foi descongelada, o excesso de água retirado e novamente congeladas para serem liofilizadas. Obteve-se um sólido escuro na forma granular.

4. Experimentos de caracterização do vermicomposto

4.1. Titulação potenciométrica
As titulações com $\mathrm{NaOH}$ em força iônica constante, foram executadas no sistema potenciométrico, com eletrodo combinado $\mathrm{Ag} / \mathrm{AgCl}$, interfaceado a um microcomputador $\mathrm{O}$ titulante foi adiciona por um sistema automatizado, sendo o voluen sendo o volume do titulante e o pH da solução medidos após cada adição. A concentração de ácido húmiinicial era de $6 \mathrm{~g} \mathrm{~L}^{-1}$.

O sistema de titulação, desenvolvido no Laboratório de Instrumentação e Quimiometria da UFV, foi baseado no potenciômetro da ORION, onde a propulsão do titulante é feita através de uma bomba peristáltica IZMATEC e, o controle das injeções, através de válvulas solenóides de "teflon".

Todo o sistema foi gerenciado, e os dados adquiridos por um programa desenvolvido em $\mathrm{Vi}$ sual Basic. As curvas de titulação foram preparadas no programa Microcal Origin.

4.1.1. Análise por regressão não-linear

Utilizou-se um programa de ajuste multiparamétrico baseado em regressão não-linear, modificado do original, utilizado por Masini, Abate e Lima [13]. O programa usa a equação geral que descreve a titulação de mistura de um ácido forte com $\mathrm{N}$ ácidos fracos, ou seja:

$f\left(V, H^{+}\right)=\left(V-V_{H_{1}}\right) C_{B}+\left\{\left[H^{+}\right]-\frac{K_{W}}{H^{+}}\right\}\left(V_{O}+V\right)-\sum_{N=1}^{V}\left\{\left(V_{H H_{0}}-V_{H_{H_{N-1}}}\right) A_{N} C_{B}\right\}$

em que $\mathrm{V}$ é o volume do titulante e $\mathrm{V}_{\mathrm{o}}$ é o volume inicial presente na cela antes do início

da titulação; $\mathrm{V}_{\mathrm{HA}_{0}} \mathrm{e} \mathrm{V}_{\mathrm{HA}_{\mathrm{N}}}$ são, respectivamente, o volume de equivalência para o ácido forte para o sítio ionizável $\mathrm{HA}_{\mathrm{N}} ; \mathrm{K}_{\mathrm{w}}$ é a constante de ionização da água a $25^{\circ} \mathrm{C}$ e $\mathrm{C}_{\mathrm{D}}$ é a concentração $A_{N}=K_{H A_{N}} /\left(H A_{N}+\left[H^{+}\right]\right)$em que $\mathrm{K}_{\mathrm{HA}}$ é

a constante de ionização do sítio $\mathrm{HA}_{\mathrm{N}}$ $\mathrm{V}_{\mathrm{HA}}$ e $\mathrm{K}_{\mathrm{HA}}$ são os parâmetros ajustáveis no cálculo, o qual é realizado, minimizando-se o erro da soma, $\mathrm{S}=\sum_{\mathrm{j}=1}^{\mathrm{m}}\left[\mathrm{pH}_{\text {j(med) }}-\mathrm{pH}_{\mathrm{j} \text { (cale })}\right]^{2}$ em que $\mathrm{m}$ é o total de dados $(\mathrm{V}, \mathrm{pH})$ usados na regressão, $\mathrm{pH}_{\text {(med) }}$ refere-se ao $\mathrm{pH}$ experimental e $\mathrm{pH}_{(\mathrm{cal})} \mathrm{o} \mathrm{pH}$ calculado. Os valores de $\mathrm{pH}$ foram calculados, usando-se uma sub-rotina baseada no método Newton-Raphson. 


\subsection{Análise termogravimétrica}

As medidas termogravimétricas foram realizadas em uma termobalança SHIMADZU, modelo TGA-50, em atmosfera dinâmica de $\mathrm{N}_{2}(150$ $\mathrm{mL} \min ^{-1}$ ), utilizando-se amostras com massa de 6 a $15 \mathrm{mg}$, em cadinho de platina, com granulometria entre 325 a 400 mesh, a uma taxa de aquecimento de $10^{\circ} \mathrm{C}$ min $^{-1} \mathrm{e}$ temperatura final de 1.000 mento
${ }^{\circ} \mathrm{C}$.

4.3. Análise espectrométrica por difração de raios $X$

Os difratogramas foram obtidos de lâminas escavadas com amostras de AHs em um difratômetro RIGAKU, com goniômetro horizontal com tubo de cobre e filtro de níquel (radiação $\mathrm{CuK} \alpha$ ), de 10 a $50^{\circ} 2 \theta$, com velocidade angular de $4 \quad 2 \theta$ / min. Para digitalização dos dados, foi utilizado o programa raios X, desenvolvido pelo Departamento de Solos da UFV.

4.4. Análise espectrofotométrica no uv/visível

As leituras na faixa do uv/visível foram feitas em um espectrofotômetro HITACHI, modelo U2000, utilizando-se células de quartzo com caminho ótico de $10 \mathrm{~mm}$. Utilizou-se cerca de $2 \mathrm{mg}$ ajuste do $\mathrm{pH}$. Na faixa do visível, as absorvâncias em 465 e $665 \mathrm{~nm}$ e a relação entre estas $\left(E_{4} / E_{6}\right)$ foram utilizadas.

\subsection{Análise espectrofotométrica no in-} fravermelho

Utilizou-se um espectrofotômetro modelo Perkin Elmer (FT-IR 1000). Obtinham-se os espectros com pastilhas preparadas com $100 \mathrm{mg}$ de $\mathrm{KBr}$ pulverizado e secado a $110{ }^{\circ} \mathrm{C}$ e $1 \mathrm{mg}$ de ácido húmico de vermicomposto. A leitura foi feita na faixa de $4.000-400 \mathrm{~cm}^{-1}$

\section{Resultados e Discussão}

\section{Titulação potenciométrica}

Foram obtidas curvas de titulação das 30 mostras utilizando-se cerca de 70 pontos.

Utilizou-se para ajuste dos dados com os seguintes valores: $V_{\text {máximo }}=20 \mathrm{~mL}$; Vazão $=1,852$ $\mathrm{g} \mathrm{min}^{-1}$; Incremento =0,1 mL; Resolução: 0,003. A calibração dos eletrodos foi feita a parti da titulação de $25 \mathrm{~mL}$ de solução de $\mathrm{HCl}$ 0,1046 mol L-1 com 50 mL de solução-padrão de $\mathrm{NaOH}$ $0,1026 \mathrm{~mol} \mathrm{~L}^{-1}$.

\subsection{Regressão não-linear}

Através de gráficos de derivadas de titulações dos AHs, conseguiu-se pré-estabelece um valor inicial para a constante de dissociação de grupos carboxílicos e fenólicos. Foi traçado o gráfico de $d \mathrm{pH} / d \mathrm{~mL}$ como função do $\mathrm{pH}$ e depois a segunda derivada $\left(d \mathrm{pH}^{2} / d^{2} \mathrm{~mL}\right)$; o valor no qual esta tendia a zero fornecia o volume de equivalência aproximado para cada grupo ácido.

Aos dados obtidos nas titulações, aplicou-se, então, o programa de ajustes por regressão não-linear modificado, para diferenciar os grupos ácidos, permitindo a determinação dos $\mathrm{pK}$

No caso de AHs de vermicomposto, consideraram-se 11 parâmetros a serem calculados pelo programa, sendo um deles o volume para neutralizar o excesso de ácido forte; os outros 10 referentes aos volumes de neutralização de cada um dos cinco ácidos fracos e respectivos pKs.

Os valores atribuídos inicialmente são baseados no gráfico da derivada segunda, a partir do qual é possivel estabelecer um intervalo possível de existência de um grupo titulável e, a partir daí, refinar os valores até que estes possam convergir adequadamente. Os valores de $\mathrm{pK}$ iniciais foram baseados nos cinco valores citados por Masini, Abate e Lima [13] para AHs de vermicomposto. Utilizando o programa, verificou-se a existência de cinco constantes de equilíbrio para alguns AHs das etapas de vermicompostagem. En outros, notou-se a existência de dois dos pKs calculados com valores aproximadamente iguais ou mesmo iguais, supondo-se, portanto, a existência de dois grupos com pKs não distinguiveis pelo programa, como se verifica no Tabela 1.
Tabela 1. Resultados obtidos pela titulação de ácido húmico com NaOH 0,0981 mol L-1 com pK de cada grupo ácido com força iônica $0,5 \mathrm{~mol} \mathrm{~L}^{-1} \mathrm{e}$ temperatura de $25^{\circ} \mathrm{C}$.

\begin{tabular}{|c|c|c|c|c|c|c|c|c|c|c|c|}
\hline Amostra & $\mathrm{V}_{\mathrm{HCl}}$ & $\mathrm{V}_{1}$ & $\mathrm{pK}_{1}$ & $\mathrm{~V}_{2}$ & $\mathrm{pK}_{2}$ & $\mathrm{~V}_{3}$ & $\mathrm{pK}_{3}$ & $\mathrm{~V}_{4}$ & $\mathrm{pK}_{4}$ & $\mathrm{~V}_{5}$ & $\mathrm{pK}_{5}$ \\
\hline $1 \mathrm{Q}$ & 1,76 & 3,91 & 3,98 & 5,19 & 5,28 & 6,23 & 6,23 & 6,83 & 7,99 & 9,10 & 9,66 \\
\hline $1 \mathrm{~T}$ & 1,04 & 1,82 & 4,58 & 2,11 & 5,89 & 2,61 & 6,18 & 3,18 & 7,22 & 4,27 & 9,23 \\
\hline $1 \mathrm{~S}$ & 1,03 & 1,48 & 4,50 & 1,92 & 4,51 & 2,91 & 5,89 & 3,37 & 7,58 & 4,84 & 9,59 \\
\hline $2 \mathrm{Q}$ & 1,02 & 1,88 & 4,49 & 2,23 & 5,82 & 2,67 & 5,84 & 3,07 & 7,32 & 4,17 & 9,28 \\
\hline $2 \mathrm{~T}$ & 0,77 & 1,26 & 4,67 & 1,35 & 4,68 & 1,81 & 6,01 & 2,16 & 7,34 & 2,82 & 9,19 \\
\hline $2 \mathrm{~S}$ & 0,93 & 1,57 & 4,58 & 1,85 & 4,56 & 2,74 & 5,95 & 3,21 & 7,65 & 4,59 & 9,63 \\
\hline $3 \mathrm{Q}$ & 0,88 & 1,18 & 4,48 & 1,71 & 4,48 & 2,44 & 5,95 & 2,89 & 7,59 & 3,94 & 9,47 \\
\hline $3 \mathrm{~T}$ & 0,92 & 0,95 & 4,61 & 1,68 & 4,62 & 2,20 & 5,98 & 2,53 & 7,40 & 3,22 & 9,19 \\
\hline $3 S$ & 0,84 & 0,95 & 4,53 & 1,70 & 4,53 & 2,34 & 5,93 & 2,76 & 7,17 & 3,50 & 9,34 \\
\hline $4 \mathrm{Q}$ & 2,36 & 2,75 & 4,42 & 3,47 & 4,44 & 4,41 & 5,90 & 4,92 & 7,55 & 6,03 & 9,45 \\
\hline $4 \mathrm{~T}$ & 1,27 & 2,35 & 4,39 & 3,00 & 5,76 & 3,25 & 6,51 & 3,71 & 7,58 & 4,76 & 9,42 \\
\hline $4 \mathrm{~S}$ & 1,25 & 1,86 & 4,53 & 2,42 & 4,53 & 3,37 & 5,91 & 4,26 & 7,29 & 6,05 & 9,57 \\
\hline $5 \mathrm{Q}$ & 0,97 & 1,79 & 4,59 & 2,17 & 5,94 & 2,45 & 6,65 & 2,64 & 7,70 & 3,17 & 9,21 \\
\hline $5 \mathrm{~T}$ & 1,59 & 2,66 & 4,16 & 3,44 & 5,45 & 3,88 & 6,37 & 4,33 & 7,53 & 5,39 & 9,15 \\
\hline $5 S$ & 2,09 & 2,58 & 4,61 & 3,23 & 4,61 & 4,09 & 6,06 & 4,58 & 7,41 & 5,78 & 9,23 \\
\hline $6 \mathrm{Q}$ & 1,77 & 2,90 & 4,21 & 3,03 & 5,71 & 4,07 & 5,72 & 4,56 & 7,29 & 5,60 & 9,15 \\
\hline $6 \mathrm{~T}$ & 1,45 & 2,69 & 4,32 & 3,21 & 5,72 & 3,47 & 5,73 & 3,98 & 7,24 & 4,98 & 9,09 \\
\hline $6 S$ & 0,88 & 1,44 & 4,54 & 1,76 & 4,53 & 2,45 & 6,11 & 2,68 & 7,41 & 3,36 & 9,13 \\
\hline $7 \mathrm{Q}$ & 1,91 & 3,15 & 4,27 & 4,01 & 5,68 & 4,33 & 6,58 & 4,77 & 7,68 & 5,71 & 9,33 \\
\hline $7 \mathrm{~T}$ & 1,52 & 2,74 & 4,18 & 3,44 & 5,41 & 3,73 & 6,13 & 4,24 & 7,17 & 5,17 & 9,04 \\
\hline $7 \mathrm{~S}$ & 2,24 & 2,54 & 4,57 & 3,42 & 4,57 & 4,34 & 6,01 & 4,83 & 7,47 & 5,79 & 9,48 \\
\hline $8 \mathrm{Q}$ & 0,92 & 1,15 & 4,43 & 1,81 & 4,43 & 2,43 & 5,88 & 2,84 & 6,97 & 3,57 & 9,01 \\
\hline $8 \mathrm{~T}$ & 1,06 & 1,57 & 4,34 & 2,33 & 4,25 & 3,25 & 5,87 & 3,83 & 7,54 & 4,87 & 9,41 \\
\hline $8 \mathrm{~S}$ & 1,10 & 2,27 & 4,29 & 3,17 & 5,70 & 3,58 & 6,58 & 4,03 & 7,81 & 5,20 & 9,50 \\
\hline $9 \mathrm{Q}$ & 1,37 & 2,35 & 4,41 & 2,74 & 4,43 & 3,27 & 6,17 & 3,58 & 7,38 & 4,32 & 9,13 \\
\hline $9 \mathrm{~T}$ & 0,83 & 1,04 & 4,34 & 1,77 & 4,34 & 2,57 & 5,83 & 2,91 & 7,41 & 3,71 & 9,26 \\
\hline $9 \mathrm{~S}$ & 1,15 & 1,89 & 4,39 & 2,31 & 4,39 & 3,09 & 5,93 & 3,57 & 7,51 & 4,56 & 9,34 \\
\hline $10 \mathrm{Q}$ & 1,13 & 1,77 & 4,40 & 2,29 & 4,40 & 3,63 & 5,86 & 4,16 & 7,46 & 5,86 & 9,54 \\
\hline $10 \mathrm{~T}$ & 1,01 & 2,01 & 4,50 & 2,41 & 5,80 & 2,44 & 6,4 & 2,81 & 7,41 & 3,46 & 9,23 \\
\hline $10 \mathrm{~S}$ & 1,09 & 1,13 & 4,37 & 2,20 & 4,41 & 2,80 & 5,85 & 3,16 & 7,36 & 3,90 & 9,18 \\
\hline
\end{tabular}


O primeiro volume $\mathrm{V}_{\mathrm{HCl}}$ é correspondente ao excesso de ácido forte, e os outros cinco volumes $\left(\mathrm{V}_{1}, \ldots, \mathrm{V}_{5}\right)$ correspondem ao volume de equivalência para cada grupo titulável.

Analisando os dados tratados, foram determinadas cinco classes de grupos tituláveis, compatíveis com os resultados da literatura com relação a substâncias húmicas [13,14], sendo HA , HA

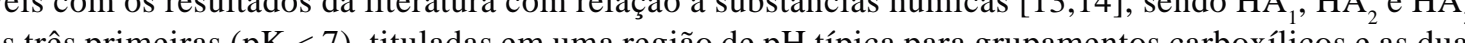
a tim pK $\mathrm{pK}_{\mathrm{a}}$ encont valor de $\mathrm{pK}_{\mathrm{a}}$ normalmente obtido para o sexto grupo em AH extraído do solo e comercial foi próximo de 10,0 e atribuído a grupos fenólicos.

Em estudo comparativo, Shin, Monsallier e Choppin [15] demonstraram ocorrer alteração química com alguma perda de grupos carboxílicos no AH purificado em relação ao não-purificado.

Na Figura 1 comparou-se a curvas de titulação experimental com a curva ajustada pelo programa de regressão não-linear, sendo que, a maior parte da curva gerada coincidiu com a curva de titulação real, evidenciando um bom ajuste pelos dados gerados.

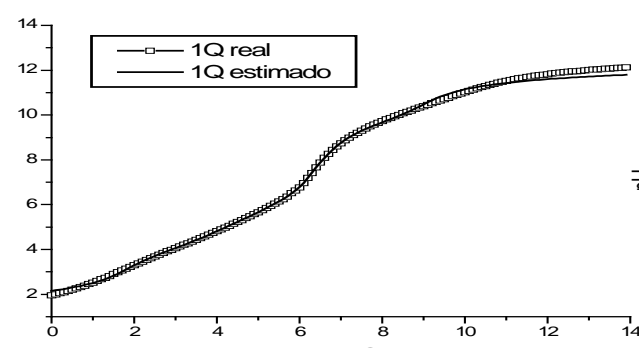

동

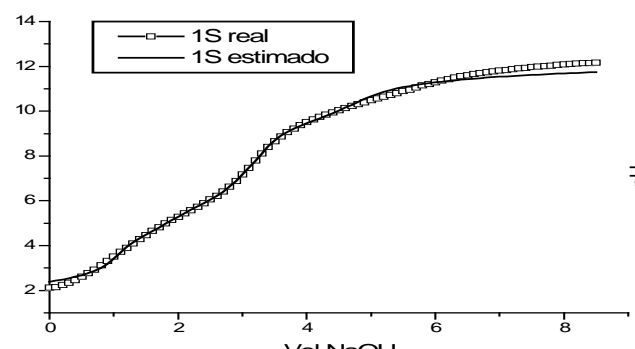

퐁

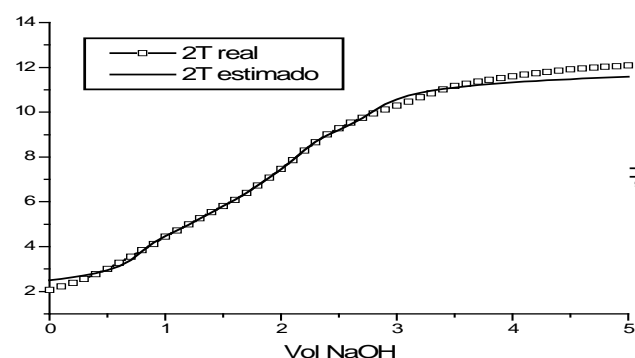

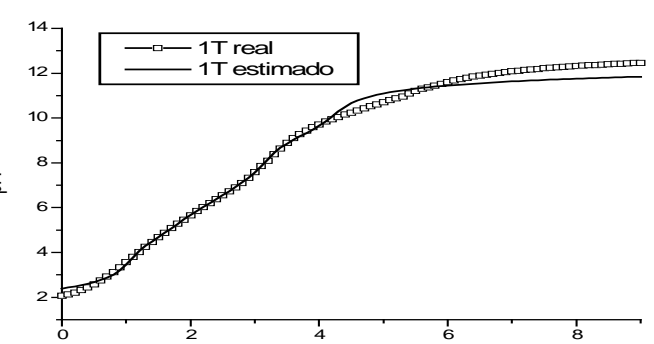
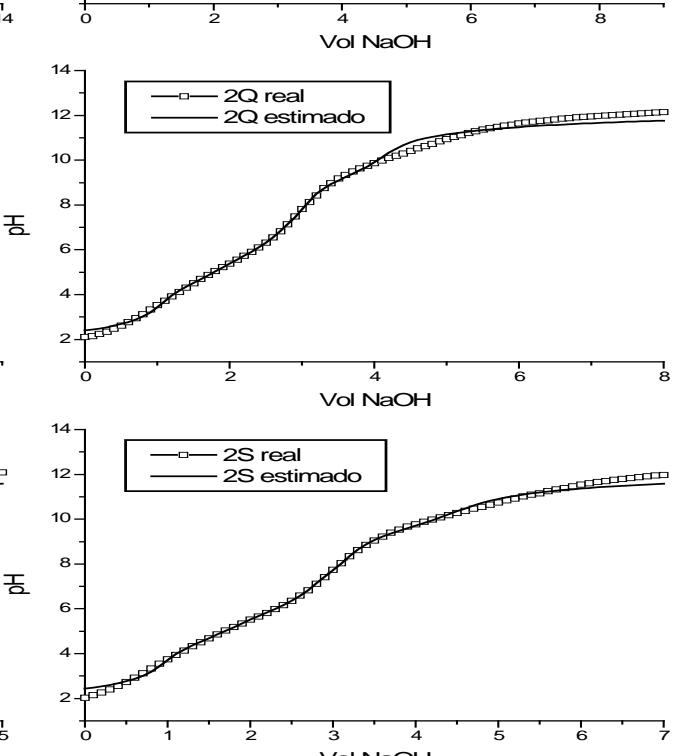

$\mathrm{Vol} \mathrm{NaOH}$
Figura 23: Curvas de titulação e ajustes por regress
das amostras 1Q, 1T, 1S, 2Q, $2 \mathrm{~T}$ e $2 \mathrm{~S}$.

Figura 1. Curva de titulação experimental de ácido húmico com $\mathrm{NaOH}$ e ajustada por regressão não-linear da amostra $2 \mathrm{~S}$

\section{Análise termogravimétrica}

Para ácidos húmicos, é comum utilizar a razão da perda de massa versus temperatura (curva TG), em que se observam dois picos principais. O primeiro, em baixa temperatura $\left(\approx 260^{\circ} \mathrm{C}\right)$, é atribuído decomposição de celulose; o outro, em temperatura mais elevada $\left(>400^{\circ} \mathrm{C}\right)$, relacionado com a decomposição de celulose+lignina [16].

As principais etapas da pirólise que as substâncias húmicas geralmente admitem são desidratação até $473 \mathrm{~K}$, eliminação dos grupamentos funcionais entre 520 e $580 \mathrm{~K}$ e decomposição do "núcleo central" a uma temperatura superior a $673 \mathrm{~K}$.

A decomposição térmica foi um processo complexo, ocorrendo em duas etapas superpostas. A comparação da curva TG com sua primeira derivada, permitiu localizar o ombro a $400{ }^{\circ} \mathrm{C}$ e confirmar 0 decaimento a $260^{\circ} \mathrm{C}$ (Figura 2)

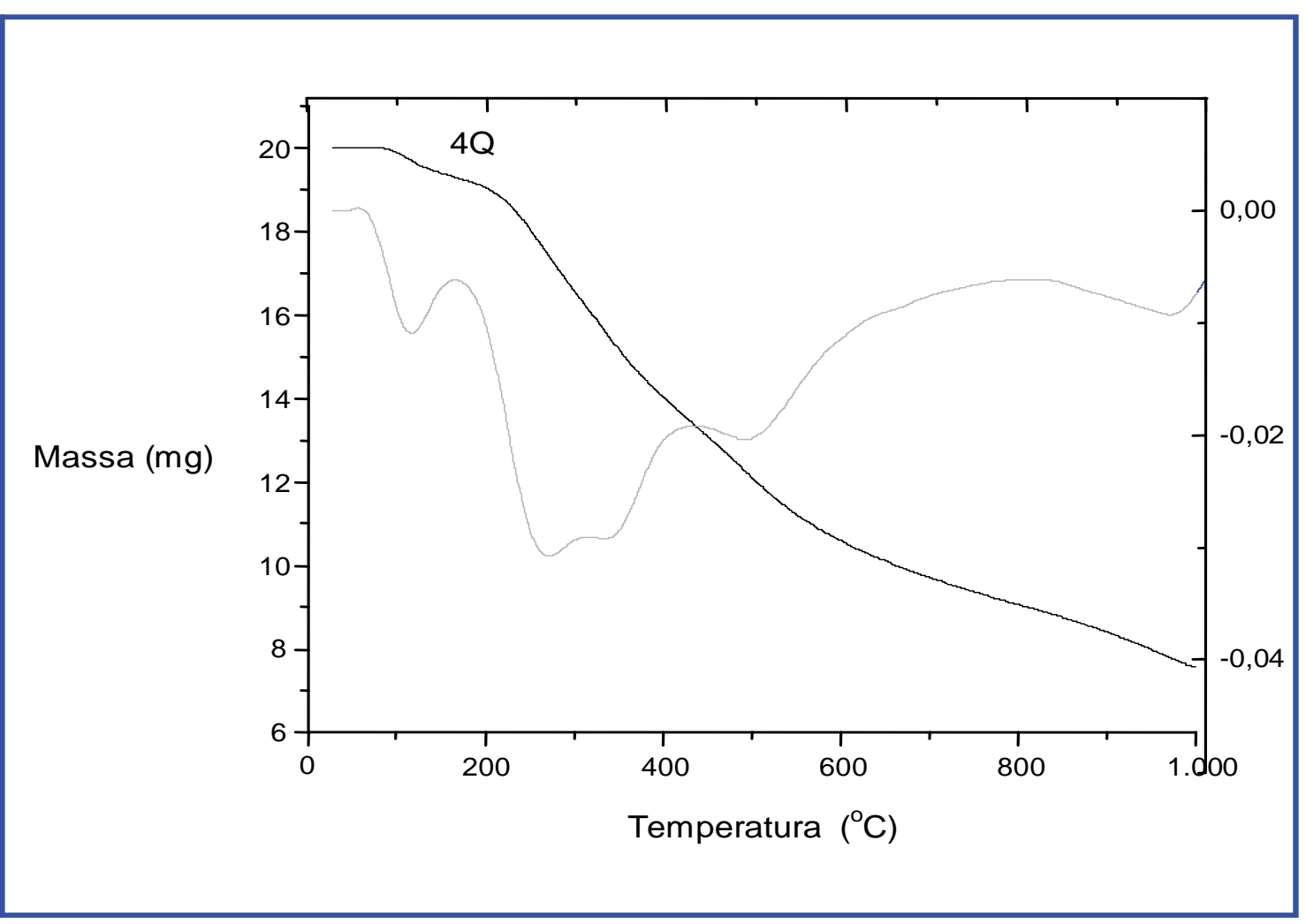

Figura 2. Curva de TG/DTG, em atmosfera de $\mathrm{N}_{2}$, cadinho de platina a $10^{\circ} \mathrm{C}$ min $^{-1}$, amostra $4 \mathrm{Q}$.

A primeira reação representou a separação de estruturas alifáticas e, ou, alicíclicas e, a segunda, a decomposição de estruturas aromáticas, sendo mais rápida que a segunda. Assim, é esperado que exista algum tipo de diferença de natureza estrutural, talvez em nível molecular:

A estabilidade térmica dos ácidos húmicos foi estudada por meio das medidas termogravimétricas em nitrogênio. As curvas indicaram que a perda do peso foi de 52,5 \% a 91,7 \% de massa total, com a ressalva de que, em média, $73,19 \%$ ocorriam abaixo de $400{ }^{\circ} \mathrm{C}$ (Tabela 2), o que foi indicativo de uma proporção pequena de estruturas aromáticas. 
Tabela 2. Resultados de perda de massa das 30 amostras de ácidos húmicos

\begin{tabular}{cccccccccccc}
\hline \multirow{2}{*}{ Perda de Massa } & Leira & \multicolumn{10}{c}{ Semana } \\
\cline { 2 - 12 } & & 1 & 2 & 3 & 4 & 5 & 6 & 7 & 8 & 9 & 10 \\
\hline \multirow{3}{*}{ Após 400 ${ }^{\circ} \mathrm{C}(\%)$} & Q & 50,9 & 20,5 & 28,6 & 31,7 & 19,6 & 32,4 & 35,5 & 21,9 & 22,3 & 21,9 \\
& T & 27,8 & 30,9 & 25,6 & 19,7 & 22,1 & 33,9 & 21,9 & 20,9 & 20,7 & 24,0 \\
& S & 22,4 & 19,8 & 21,0 & 42,3 & 26,5 & 22,2 & 38,2 & 20,7 & 21,2 & 37,1 \\
Total (\%) & Q & 91,7 & 56,9 & 57,6 & 62,1 & 52,5 & 63,0 & 68,9 & 52,6 & 54,0 & 55,4 \\
& T & 61,4 & 59,7 & 59,2 & 58,1 & 53,7 & 65,9 & 55,8 & 53,0 & 52,5 & 55,7 \\
& S & 53,0 & 57,3 & 56,9 & 76,7 & 59,2 & 55,3 & 70,5 & 53,1 & 54,0 & 69,6 \\
\hline
\end{tabular}

Considerando que grupos funcionais e cadeias alifáticas se decompõem $\sim 30{ }^{\circ} \mathrm{C}$ e que os núcleos aromáticos o fazem em temperaturas $>400^{\circ} \mathrm{C}$, concluiu-se que os AHs nas amostras $1 \mathrm{Q}, 2 \mathrm{~T}, 4 \mathrm{Q}, 4 \mathrm{~S}$, 6Q, 6T, 7Q, 7S e 10S apresentam estrutura aromática em maior proporção do que nas amostras menos maturadas, já que a perda de massa foi mais lenta. Observou-se que a amostra de 65 dias de vermicompostagem apresentou um dos maiores teores de estruturas aromáticas.

Os resultados obtidos foram promissores e indicaram a utilidade do DTG na análise do processo de humificação, estando de acordo com os encontrados em AHs por Busnot et al. [8].

Houve coincidência no comportamento de variação de perda de massa após $400^{\circ} \mathrm{C}$ entre as leiras Q e S, sendo a única diferença observada da $5^{\mathrm{a}}$ para $6^{\mathrm{a}}$ semana onde uma teve um aumento (Q) e a outra uma diminuição (S). A partir da $8^{\text {a }}$ semana ocorreu uma estabilização no grau de aromaticidade, indicando, 0 término do processo. A amostra $10 \mathrm{~S}$ alcançou aum esto açatuado na perda de massa, mostranto talvez uma diferenciação na composição da leira S (Figura 3).

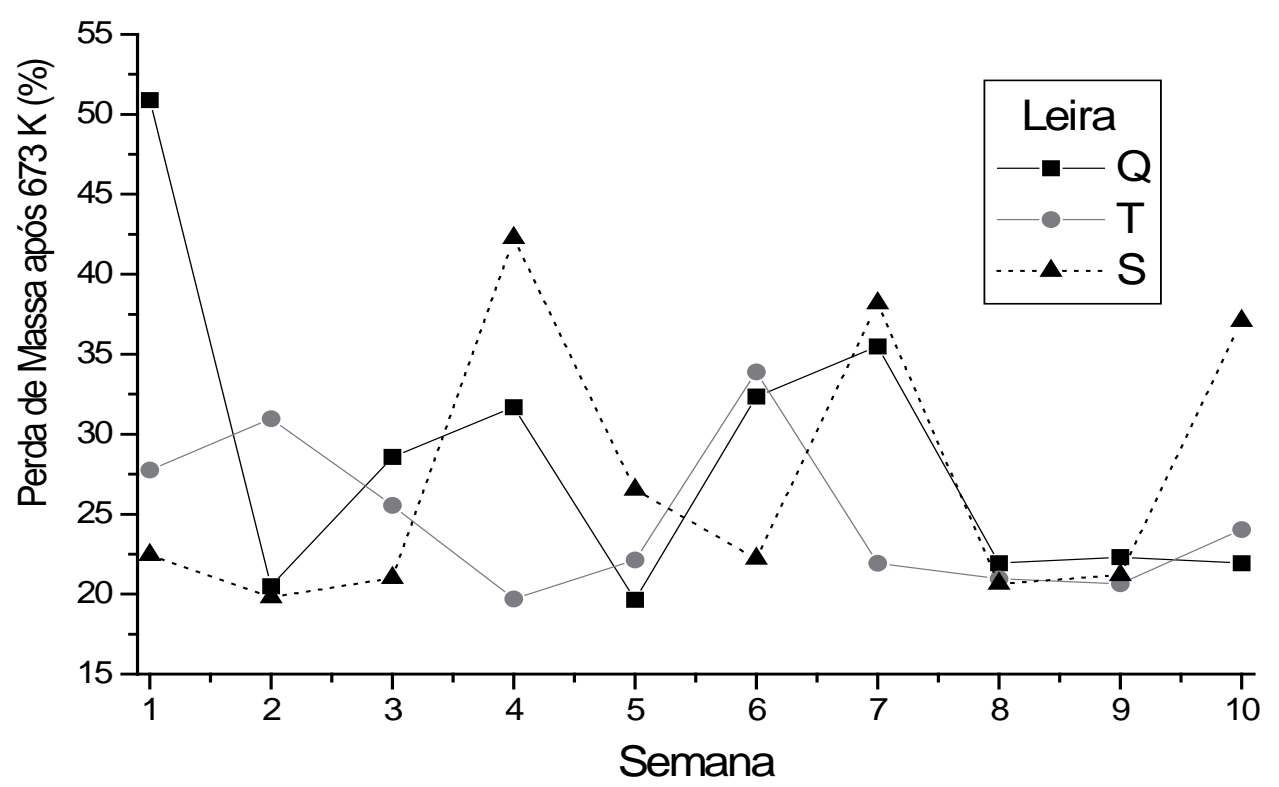

Figura3. Acompanhamento da perda de massa das amostras de ácidos húmicos ao longo do tempo de vermicompostagem.
O fato de o AH não ter sido purificado provocou aumento no resíduo como previsto por Campanella e Tomasseti [17].

. Análise espectrométrica por difração de raios X

Uma difração-padrão de ácido húmico mostra usualmente bandas próximas de $3,5 \AA$ devido à condensacão de anéis aromáticos. A intensidade e a extensão dessas bandas serão dependentes da constituição dos compostos húmicos, isto é, do grau de aromaticidade e da natureza dos componentes alifáticos, como carboxílico (-COOH) e hidroxílico $(-\mathrm{OH})$. Um aumento na banda de 3,5 §̊ indicará decréscimo no número de anéis condensados e imperfeição na sua estrutura [9].

A sobreposição dos difratogramas dos AHs evidenciou aumento de cristalinidade com o transcorrer do processo de vermicompostagem, caracterizando a presença de lignina e metabólitos microbiológicos, sendo a amostra do $1^{\circ}$ dia completamente amorfa aos raios $\mathrm{X}$, na faixa estudada, o que evidenciou abundância em matéria orgânica carbonizada, enquanto nas demais vão se definindo cerca de 15 picos, sendo os principais correspondentes aos espaçamentos 0,718; 0,417; 0,359; 0,243; e 0,170 nm (Figura 4). Desses, os três primeiros são os que mais variaram durante o processo, e o correspondente ao espaçamento de $0,359 \mathrm{~nm}$ foi 0 último a se definir, apresentando amplitude máxima a partir do $49^{\circ} \mathrm{dia}$. Schnitzer, Kodda

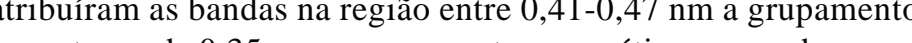
to semelhante ao do plano (002) do grafite.

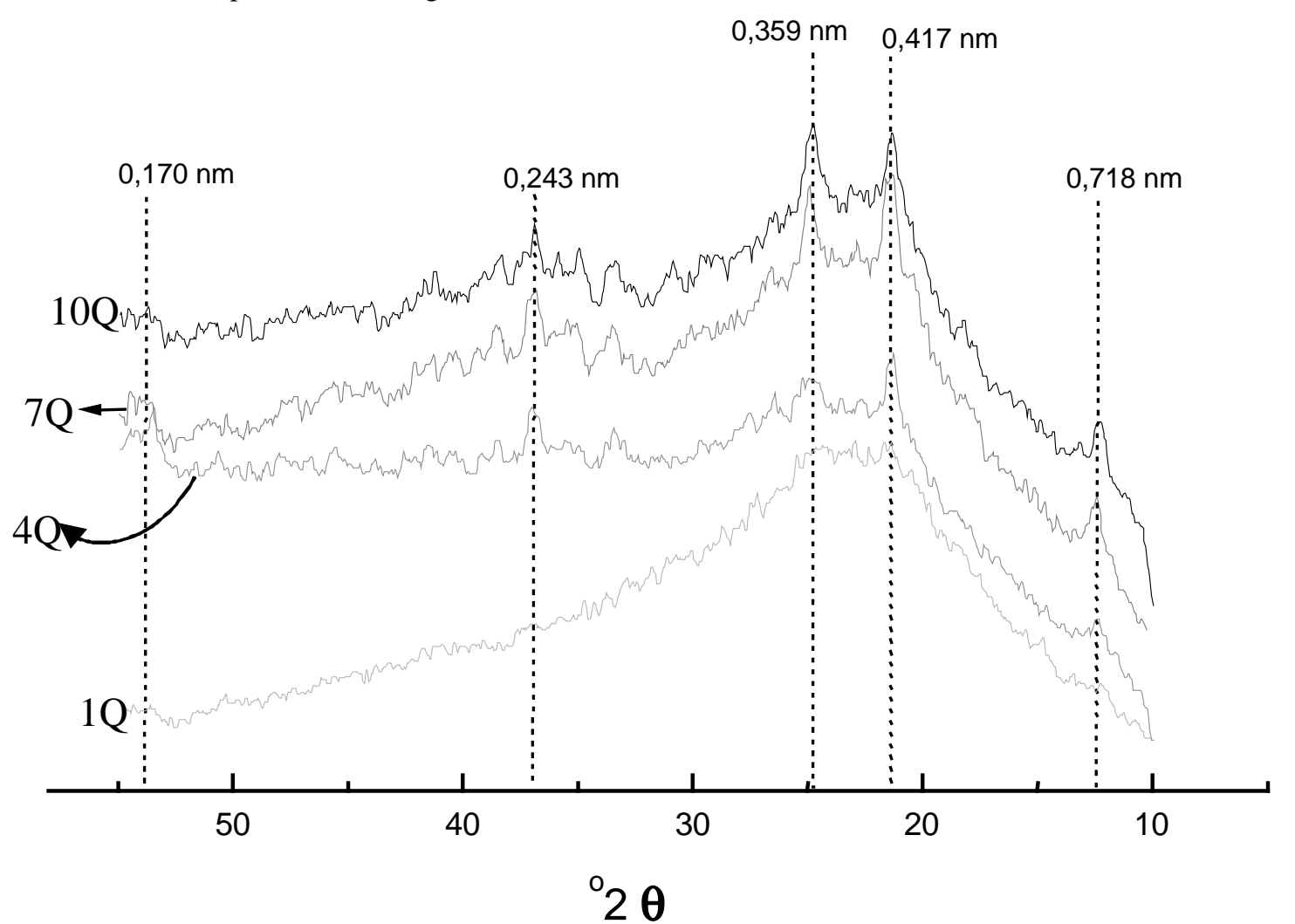

Figura 4. Exemplo de difratogramas de raios $\mathrm{X}$ das amostras de AHs 1Q, 4Q, 7Q e 10Q. 
Os resultados obtidos apresentaram-se coerentes com essas expectativas, uma vez que os picos que correspondem aos espaçamentos de 0,718 e 0,417 nm tiveram evolução simultânea e atingiram o máximo antes do espaçamento de $0,359 \mathrm{~nm}$, que corresponderia aos núcleos aromáticos. Uma vez que os principais picos somente se definiram apos a sétima semana e esperado que a polimerizaça namento cristalino dos ácidos húmicos não ocorram totalmente nos 30 primeiros dias de decomposição ativa.

É possível verificar alterações nos difratogramas de raios X, onde ocorrem variações na intensidade dos picos durante todo o processo. A amostra $2 \mathrm{~S}$ também não apresentou os picos presentes nas demais. Esses resultados obtidos apontaram para uma grande utilidade da difração de raios X no acompanhamento do processo de humificação, uma vez que diferenças marcantes de cristalinidade e ordenamento dos átomos dos ácidos húmicos foram observadas. Isso parece indicar que o processo de humificação não se dá com grandes diferenciações na composição qualitativa dos grupamentos funcionais da mistura, mas sim com reorganização estrutural e possivel polimerização de grupamentos de menor massa molar. Contudo, esse processo ainda é um campo aberto para maiores elucidações.

\section{Análise espectrofotométrica no uv/visível}

O espectrofotômetro utilizado apresentou uma porta serial (RS-232), que permitiu o interfaceamento com microcomputador. Dessa forma, os resultados provenientes da análise as análises puderam ser adquiridos e salvos utilizando um software de gerenciamento e aquisição de dados desenvolvido em Visual Basic.

Nos espectros uv/visível de ácidos húmicos, a absorção diminui com comprimento de onda crescente e dá pouca informação estrutural. Com a maioria das amostras, entretanto, um ombro na região de 250-270 nm é observado (Figura 5).

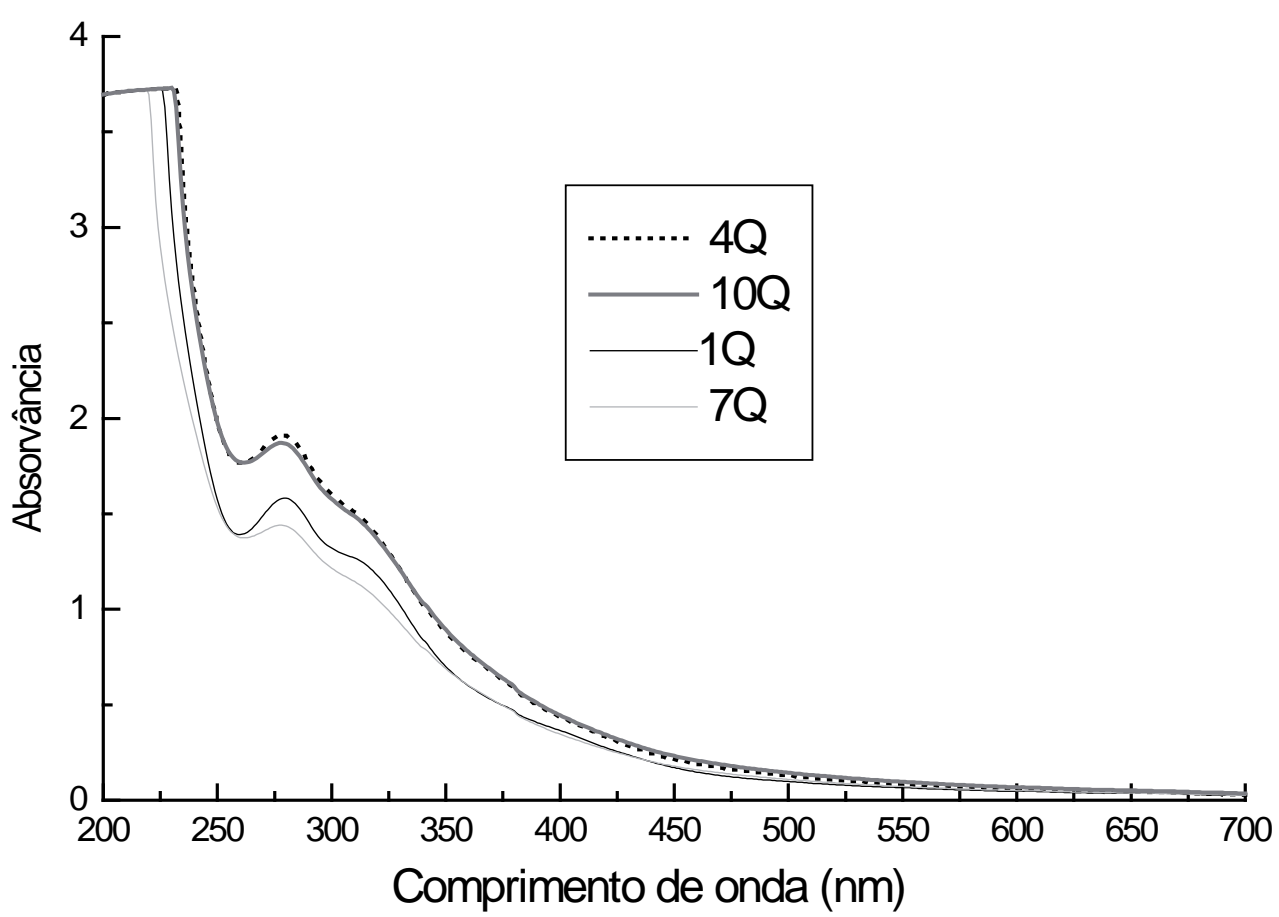

Figura 5. Exemplo de espectro de uv/visível de ácido húmico extraído de vermicomposto - amostras 1Q $4 \mathrm{Q}, 7 \mathrm{Q}$ e $10 \mathrm{Q}$.
A razão $\mathrm{E}_{4} / \mathrm{E}_{6}$ é governada principalmente pelo peso molecular médio e tamanho das cadeias que constituem o ácido húmico. Nas amostras estudadas, os valores da razão $\mathrm{E}_{/} / \mathrm{E}_{6}$ sofrem pequenas variações, sendo os valores mais baixos obtidos nas amostras das duas primeiras semanas. Dentre estas, a amostra 2S apresentou o menor valor, assim como na análise da difração de raios X. Nas outras amostras, não houve variação relacionada com o tempo de maturação, indicando que não houve mudanças no tamanho das cadeias durante esse período. Os valores encontrados estão de acordo com o esperado para ácidos húmicos, o qual geralmente é menor do que 5,0 [19]. Na Tabela 3 são apresentados os resultados da razão $\mathrm{E}_{4} / \mathrm{E}_{6}$ para as 30 amostras.

Tabela 3. Razão E/E das amostras de ácidos húmicos de vermicomposto

\begin{tabular}{ccccccccccc}
\hline \multirow{2}{*}{ Leira } & \multicolumn{10}{c}{ Semana } \\
\cline { 2 - 12 } & 1 & 2 & 3 & 4 & 5 & 6 & 7 & 8 & 9 & 10 \\
\hline Q & 3,63 & 3,14 & 4,18 & 4,31 & 3,94 & 4,29 & 4,31 & 3,86 & 4,24 & 4,21 \\
T & 3,27 & 3,50 & 4,02 & 4,36 & 4,24 & 4,65 & 4,21 & 4,28 & 4,09 & 4,24 \\
S & 3,82 & 2,96 & 4,19 & 4,77 & 4,30 & 4,42 & 4,48 & 4,60 & 4,40 & 4,37 \\
\hline
\end{tabular}

Verifica-se que ocorre uma variação brusca na razão $\mathrm{E} / \mathrm{E}$ durante as duas primeiras semanas e estes valores continuam oscilando a cada semana, mas é interessante notar que os valores obtidos para as amostras extraídas das leiras $\mathrm{S}$ e $\mathrm{Q}$ têm sempre comportamentos semelhante de aumento ou diminuincoerência ocorreu na oitava semana, sendo que a tendência após a nona semana é de estabilização do processo (Figura 6).

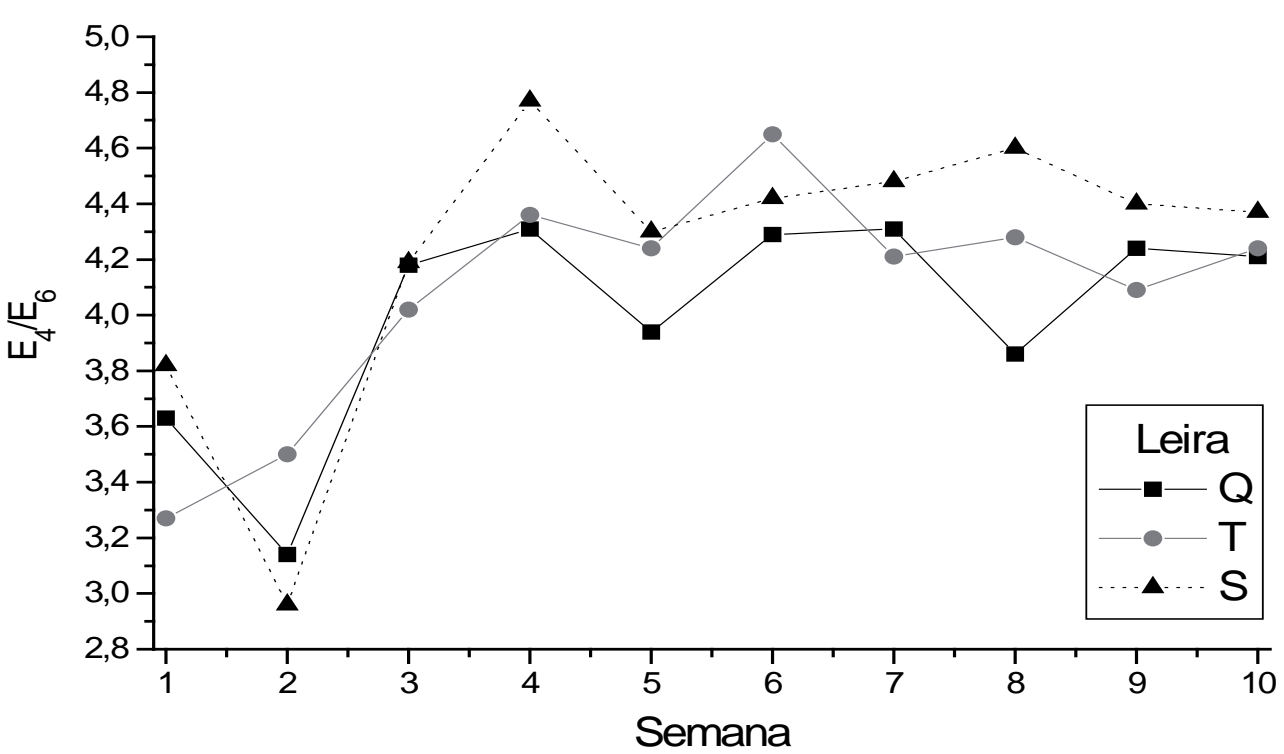

Figura 6. Razão $\mathrm{E}_{4} / \mathrm{E}_{6}$ obtida do espectro de uv/visível de ácido húmico extraído de vermicomposto das leiras S, T e Q. 
Os espectros apresentaram bandas características de grupos fenólicos e carboxílicos, mas as diferenças espectrais foram praticamente inexistentes.

O espectro apresentado na Figura 7 é um exemplo do que ocorreu de maneira geral. Apresentou, na região de 3.500-3.000 $\mathrm{cm}^{-1}$, banda forte e larga, centrada em aproximadamente $3.400 \mathrm{~cm}^{-1}$, que pode ser atribuída ao estiramento $v(\mathrm{O}-\mathrm{H})$, que corresponde a vários grupos contendo $\mathrm{OH}$ fenólico. Há também uma band localizada na regino de 1.750-1.500 $\mathrm{cm}^{-1}$, onde aparecram os estiramentos v(C=O)

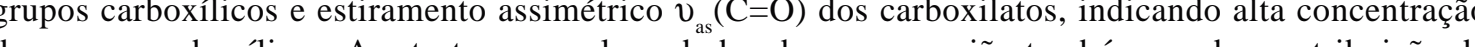
de grupos carboxilicos. A estrutura complexa de bandas nessa região tanbên recebe contrição da deformação d $(\mathrm{N}-\mathrm{H})$ e do estiramento $(\mathrm{C}=\mathrm{C})$ aromático. Essas basdas encontradas estão de acordo com trabalhos feitos anteriormente [7, 13, 20].

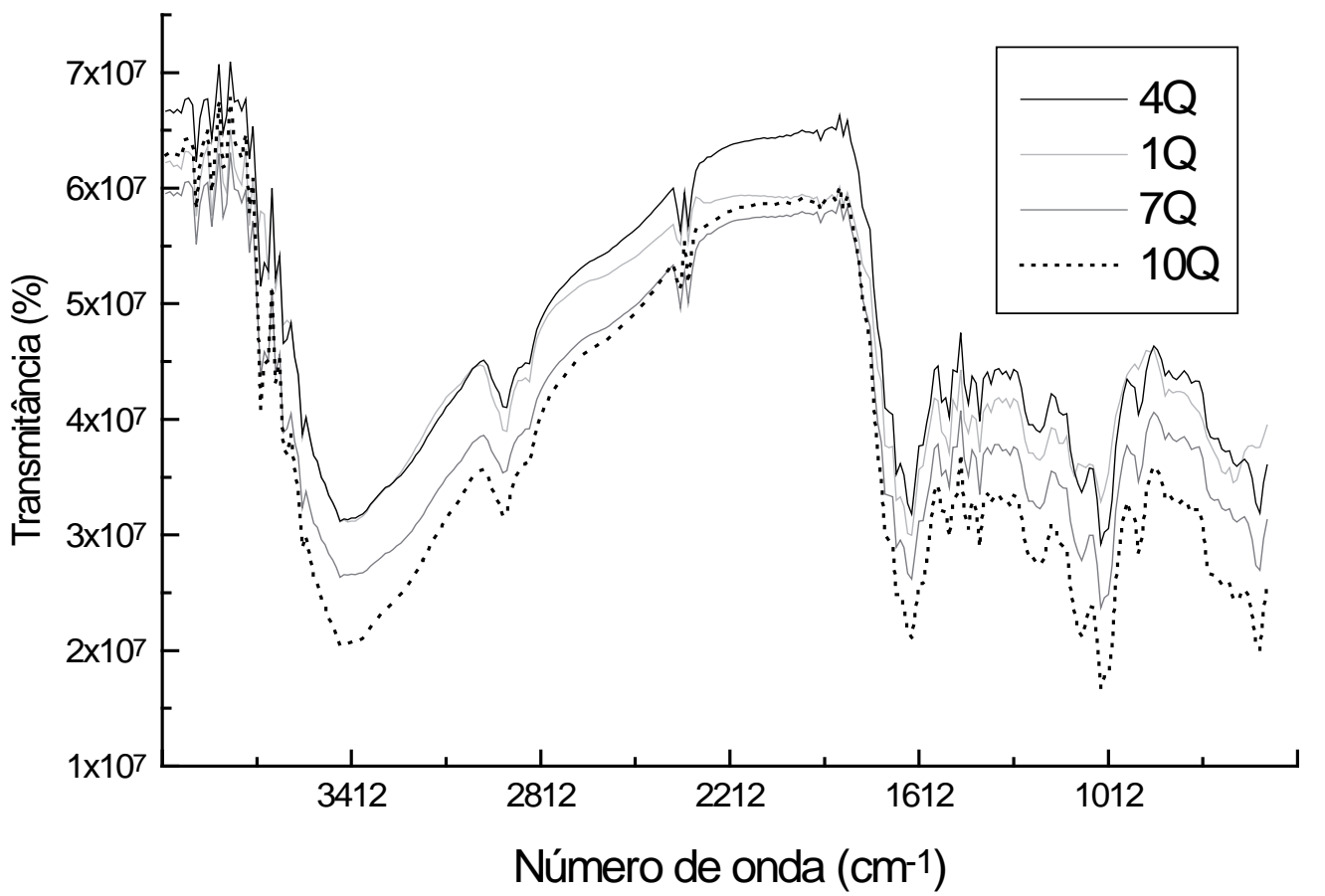

Figura 7. Espectro de infravermelho de ácido húmico extraído de vermicomposto - amostras 1Q, 4Q, 7Q e 100

A banda localizada na região de $3.000-2800 \mathrm{~cm}^{-1}$ é atribuída ao estiramento v(C-H). Há ainda uma banda na região entre 1.120-1.050 $\mathrm{cm}^{-1}$ que pode ser atribuída ao estiramento v(C-O) de álcoois, que aparece nos espectros de quase todas as amostras, à exceção da $1 \mathrm{Q}$.

Os espectros apresentaram aspectos muito similares, com picos característicos em determinadas regiões, variando de intensidade, mas com poucas variações nas freqüências de absorvância. Na comparação de espectros de ácidos húmicos extraídos de diferentes etapas do processo de vermicompostagem, poucas diferenças foram observadas.

Na Tabela 4 são apresentados alguns picos característicos de ácido húmico de vermicomposto citados por Landgraf, Silva e Rezende [21]

\begin{tabular}{ll}
\hline Número de Onda/ $\mathrm{cm}^{-1}$ & Atribuição \\
$3.500-3.000$ & Estiramento O-H de OH fenólico \\
$3.000-2.800$ & Estiramento C-H cíclico e alifático \\
$1.720-1.750$ & $v(\mathrm{C}=\mathrm{O})_{\text {CooH }}$ \\
$1.650-1.500$ & $\left.\mathrm{v}_{\mathrm{as}} \mathrm{C}=\mathrm{O}\right)_{\text {Coo- }} \mathrm{e} / \mathrm{ou} v(\mathrm{C}=\mathrm{C})_{\text {aromático }}$ \\
1.530 & $\mathrm{v}(\mathrm{C}-\mathrm{O})_{\text {fenol }}$ \\
1.400 & $\mathrm{v}_{\mathrm{s}} \mathrm{COO}-\mathrm{e}(-\mathrm{CH})_{\text {aromático }}$ \\
$1.320-1.210$ & $v(\mathrm{O}-\mathrm{H})_{\text {fenol }}$ \\
$1.180-1.000$ & $v(\mathrm{C}-\mathrm{O})$ de álcool, éter e éster \\
$900-650$ & $\mathrm{CH}$ aromático
\end{tabular}

$900-650$

$\mathrm{CH}$ aromático

Dessa forma, a análise espectroscópica no infravermelho dos ácidos húmicos de vermicomposto apenas confirmou a presença de grupos carboxílicos e fenólicos, não sendo possível a diferenciação nas diversas etapas da vermicompostagem.

\section{Conclusões}

A caracterização das amostras foi realizad através de titulação potenciométrica, de termogravimetria, de difratometria de raios $\mathrm{X}$, de espectrofotometria no uv/visível e no infravermelho, verificando a existência de similaridades e, ou, dissimilaridades entre as amostras, de acordo con o decorrer do processo.

O programa de ajuste por regressão não-linear mostrou-se eficiente no cálculo de pKa dos diferentes ácidos, distinguindo cinco grupos tituláveis nos ácidos húmicos estudados. As curvas de titulação obtidas apresentaram resultados satisfatórios, que puderam ser confirmados pela sobreposição quase que total das curvas geradas pelo programa.

As bandas presentes nos espectros do infravermelho apenas confirmaram a presença de grupos carboxílicos e fenólicos nas amostras. Com o resultado da espectrofotometria no uv/visível foram calculadas as razões $E_{4} / E_{\text {o difer }}$ diando as fortras das dus pris
Os difratogramas de raios $\mathrm{X}$ apresentaran diferenças marcantes, indicando uma reorganização estrutural nas amostras estudadas. Três picos foram identificados em quase todas as mostras.

Os termogramas apresentaram dois picos principais atribuídos à eliminação de grupamento funcionais e à decomposição de estruturas aromáticas.

Pelos resultados obtidos verificou-se que o ácido húmico de vermicomposto aqui estudado mantém suas principais características, mas sofre transformações estruturais, como o aumento da cristalinidade. 
Abstract: Samples of materials, collected at different stages of vermicompostaging, were submitted to extraction procedures of humic acids. Titration, termogravimetry (DTG), X-ray diffraction, spectrophotometry in the uv/visible and infrared techniques, were used in the study of these materials. The data from the potentiometry titration analysis were submitted to adjustment by non-linear regression, determining thus five values of pKa's characteristic of five classes of titrable groups. In the DTG curves two stages can be observed, being the first one characteristic of the separation of aliphatic and/or alycyclic structures and the second of decomposition of aromatic structures. The X-ray diffraction technique exhibed marked differences in the results, mainly in the first three peaks, were a structural reorganization and a polymerization along the vermicompostaging process. The infrared spectra practically no differentiation between the samples. The values for the ratio $\mathrm{E}_{4} / \mathrm{E}_{6}$ found are in accordance with the characteristic values for humic acids, but do not supply information that can contribute to the elucidation of the structure and formation of these acids.

Keywords: titration, termogravimetry, diffraction, spectrophotometry, non-linear regression.

\section{Referências Bibliográficas}

[1] D. J. Silva, M. F. Lima, Rev. Bras. Frutic., 23(3) (2001) 139.

[2] A. M Aquino, D. L. Almeida, J. G. M. Guerra e H. DePolli, Pesq. Agropec. Bras., 40(11)(2005)

[3] H. R. Schulten, M. Schnitzer, Soil Science, 162(1997)115. [4] S. L. Moraes, M. O. O. Rezende, Química Nova, 27(2004)701.

[5] S. B. Ceppi, M. I. Velasco, C. P. De Pauli, Talanta, 50(1999)1057.

[6] G. Abate, E. C. Lima, J. C. Masini, Anais... In: Enc. Bras. Subst. Húmicas, 2(1997) 152.

[7] Z. Tao, J. Zhang, J. Zhai, Analytica Chimica Acta, 395(1999)199.

[8] A. Busnot, F. Busnot, J. F. Le Querler, J. Yazbeck, Thermochimica Acta, 254 (1995)319.

[9] M. Adhikari, J. K. K. Chakrabarti, Indian Chem. Soc. 60 (1983)566.

[10] P. MacCarthy, J. A. Rice, In: Aiken et al. (Eds.). Humic substances in soil, sediment and water: geochemistry, isolation and characterization. New York: John Wiley \& Sons, 1985. cap. V.

[11] Y. Chen, N. Senesi, M. Schnitzer, Soil Sci. Soc. Am. J., 41 (1997) 352.

[12] F. J. Stevenson, Humus chemistry. New York: Wiley, 1982. 443p.

[13] J. C. Masini, G.Abate, E. C. Lima, Analytica Chimica Acta, 364 (1998) 223.

[14] S. L. Moraes, M. D.Landgraf, M. O. O. Rezende, Eclet. Quím., 29(2)(2004)47.

[15] H. Shin, J. M. Monsallier, G. R. Choppin, Talanta. 50 (1999) 641.

[16] G. Ricca, L. Frederico, C. Astori, R. Gallo, Geoderma. 57 (1993) 263.
[17] L. Campanella, M. Tomassetti, Termochimica Acta. 170(1990)67.

[18] M. Schitzer, H. Kodama, J. A. Rimpeester Soil Sci. Soc. Am. J. 55(1991)745.

[19] L. S. Silva, T. N. Oliveira, M. A. Ballin E C. R. M. Peixoto, Eclet. Quím., 31(4) (2006) 39.

[20] A. Piccolo, F. J. Stevenson, Geoderma, 27(1982)19.

[21] M. D. Landgraf, S. C. Silva, M. O. O. Rezende, Analytica Chimica Acta, 368(1998) 155. 